\title{
AL DESCUBRIMIENTO DE Sí MISMAS
}

\author{
DISCOVERY OF THEMSELVES
}

Olga González Sarmiento ${ }^{1}$

\section{RESUMEN}

El artículo trata sobre la vida de mujeres que han sobrevivido a situaciones adversas o que han participado de manera sobresaliente en la tarea de ayudar a que otras mujeres lo hagan.

Parte de la idea de que las mujeres poseemos mucha fuerza interior, la que nos permite construirnos, reconstruirnos e, incluso, ayudar a otros a que también lo hagan, cuando sea necesario.

En una palabra, se centra en el mensaje positivo que nos da la vida de seis mujeres excepcionales, que, quizás encarnan a muchas otras con trayectorias y desarrollo similares, pero que, con sus actos, nos recuerdan que, aunque vivamos situaciones difíciles de superar, la voluntad, la fe, la entereza, el amor a los demás, el amor a nosotros mismos, nos pueden ayudar no solo a superarlas, sino a colaborar en el desarrollo y crecimiento de otros que se encuentren en situaciones parecidas.

\section{Palabras clave}

mujer, esperanza, resiliencia, autovaloración, lucha contra la opresión

\section{ABSTRACT}

The article is about the lives of women who have survived adverse situations or have participated with distinction in the task of helping other women to do so.

Part of the idea that women possess much inner strength that allows us to build ourselves, rebuild and even help others to do so, when necessary.

In short, it focuses on the positive message that give us the life of six exceptional women who, perhaps embody many others with similar backgrounds and development, but by their actions remind us that, even though we live situations difficult to overcome; will, faith, fortitude, love others, love ourselves can help us not only overcome them, but to assist in the development and growth of others who are in similar situations.

\section{Keywords}

woman, hope, resilience, self-appraisal, struggle against oppression

\begin{abstract}
"Según informó el premio Nobel, Amartya Sen, cien millones de mujeres han desaparecido. Es decir, según las estadísticas, han nacido y deberían estar vivas, pero no lo están, porque han muerto antes de tiempo".
\end{abstract}

El reconocido filósofo Julián Marías mencionó una vez que "la mujer ha sido siempre la transmisora, la portadora del sistema de creencias de una sociedad y, en este sentido, la gran educadora. Nada importante arraiga si antes no pasa por la mujer, si ella no lo adopta." (Marías, 1990, p. 24), tal afirmación podría considerarse parcialmente falsa o parcialmente cierta, dependiendo de la perspectiva desde donde se le sopese.

Cierto que las creencias nos son transmitidas desde la cuna, principalmente por nuestras

Doctora en Educación y Magister en Tecnología Educativa, con segunda especialidad en Formación Magisterial. Coordinadora de la Unidad de Investigación de la Facultad de Educación de la Universidad Femenina del Sagrado Corazón, Docente universitaria y Consultora educativa. 
madres, quienes nos trasladan día a día su visión del mundo, sus esperanzas, sus miedos, su cultura, su fe..., sin embargo, la "gran transmisora", la "portadora de creencias", con frecuencia ha sido dejada de lado y, muchas veces, se ha convertido en la "protagonista ausente" de la historia.

¿Por qué una afirmación tan extrema?, pues simplemente porque las estadísticas a nivel mundial señalan que la inmensa mayoría de las mujeres que pueblan el planeta soportan niveles extremos de pobreza, violencia, falta de derechos civiles, discriminación, carencias educacionales, sanitarias y asistenciales de primer nivel.

Podemos observar día a día que los efectos de la violencia y violación de sus derechos son experimentados por mujeres de todas las edades, que son víctimas de abandono, violencia física y psicológica, esclavitud sexual, abuso, embarazos forzados, esterilización forzada, tortura, secuestro, desapariciones y otras muchas nuevas formas de violencia.

Sin embargo, estos nuevos rostros de la violencia se expresan, muchas veces, como una carencia de recursos tan frecuente $y$ tan extrema que se empezó a hablar de la "feminización" de la pobreza. Se dice, inclusive, que, en muchos países, incluido el nuestro, la pobreza y el analfabetismo tienen rostro de mujer.

Pero, ¿qué sucede cuando, a pesar de tener en contra todos los pronósticos, la mujer se alza por encima de sus propias limitaciones $y$ es capaz de luchar sacando fuerzas de donde se las quitaron para seguir adelante, recrearse, reinventarse, transformarse $y$ contagiar con su fuerza inclusive a quienes la daban por vencida?

\section{EDNA ADAN}

Cuando se ve a esta mujer en sus cincuenta, quizás sesenta años moverse con vigor $y$ entusiasmo juveniles en medio de una cantidad de camillas y mujeres que se encuentran a punto de dar a luz, lo menos que podemos pensar es que le entusiasma lo que hace: "es mi pasión" afirma ella.

Sin embargo, en ese hospital, el único de la zona, es uno de los lugares más pobres del mundo, los habituales riesgos de dar a luz no son suficientes.

En Etiopía, la costumbre de realizar la ablación del clítoris es costumbre arraigada, se lo realizan al $90 \%$ de la población femenina entre los 5 y los 8 años de edad, Edna no fue una excepción, también, a sus 7 años tuvo que pasar por esa terrible experiencia.

Lo que muchos no conocen es que esta tradición trae consigo una serie de consecuencias a nivel físico $y$, por supuesto, psicológico. En el aspecto físico, la niña se verá impedida, posteriormente, de dar a luz por vía natural y deberá ser sometida a cesárea en cada parto, el problema es que en Somalia casi no hay hospitales que las puedan ayudar y la población es considerada de pobreza extrema, son muchas las veces que las gestantes fallecen en muy alto porcentaje cuando se ven precisadas de dar a luz y no pueden recibir la ayuda asistencial que precisan.

Sin embargo, Edna Adan rompió barreras toda su vida: fue, por ejemplo, una de las pocas mujeres que estudió en Somalia, la primera mujer de ese país que condujo un vehículo y luego, la primera en estudiar en Gran Bretaña, gracias a una beca y también se convirtió en la primera enfermera cualificada de su país.

Tuvo una carrera brillante en la Organización Mundial de la Salud, se retiró y fue entonces que hizo realidad un sueño de toda su vida, levantar un hospital en Somalilandia para lo cual utilizó hasta el último centavo que tenía, recibió ayuda de algunos donantes, principalmente norteamericanos e inició la atención en unas condiciones de higiene y atención que hasta ese momento no se conocían en ese país.

Ahora, paralelamente a su trabajo en el hospital donde, a diario salva vidas, ha capacitado, hasta el momento, a más de 1000 mujeres somalíes para que, a su vez, salven vidas en 
sus propias localidades, todas ellas sumamente alejadas de los pocos centros hospitalarios existentes.

"Sé que no hay una varita mágica que pueda solucionar todos nuestros problemas, pero estoy segura que si unimos nuestras manos y nos concentramos en una sola cosa, que es entrenar a más parteras en nuestra comunidad, evitaremos la muerte de muchas mujeres y niños", dijo hace poco Edna en una universidad surafricana". (Kristof,N.D., \&WuDunn, S.,2012, p.132)

\section{URMI BASU}

En el 2001, Urmi decide dejar de lado el estatus de aristócrata en Calcuta y decide dedicarse a velar por el futuro de niños, hijos de trabajadoras sexuales, que deambulan por las calles, solos, desnutridos, sin esperanza alguna para su vida, comprando alcohol o cigarros.

Su proyecto empieza con la construcción de un centro tipo guardería que los cuide mientras que sus madres terminan de trabajar, pero poco a poco, la idea cobró forma y, en el centro, se fueron, progresivamente, ocupando de su educación, salud y necesidades recreativas.

Sin embargo, en la India hay un sistema de castas que impide que unas interactúen con otras, así que, no es factible interactuar con una persona que se dedique al trabajo sexual sin ser estigmatizado por el resto, ya que el hecho de dedicarse a cierto tipo de trabajos contamina a la persona, la convierte en paria.

De esta manera, Urmi perdió su matrimonio y también muchos de los derechos propios de su posición privilegiada.

Todo esto hizo que dejara la vida que conocía atrás. Y empezara una nueva, una donde su objetivo fue ganarse la confianza de las mujeres de los barrios rojos, cuando lo logró, entonces, comenzó a organizarlas, a empoderarlas.

Fundó una casa de acogida que hoy tiene ya tres sedes: New Light. Allí cuida, educa y alimenta a más de 200 niños, en su mayoría, hijos de trabajadoras sexuales. Les entrega herramientas para salir de la pobreza y se esfuerza por mostrar otros caminos a las niñas, para que no sigan el tuvieron que seguir sus madres.

En este nuevo camino que Urmi ha iniciado, no le son extrañas las amenazas de distinto calibre donde ha visto, inclusive, en peligro su vida debido a que ha llegado a convertirse en un referente de la lucha contra el tráfico de mujeres y niñas prostituta en su país.

Recordemos que la India es uno de los principales receptores de tráfico sexual en el mundo.

Niñas de entre 11 y 14 años de edad, en más de un $60 \%$, son arrancadas de sus paupérrimas aldeas en Bangladesh y Nepal con la promesa de un empleo digno, o por el mero pago de una cantidad de dinero a sus familiares para, luego, terminar en burdeles de Bombay, Nueva Delhi o Calcuta donde permanecen hasta que, finalmente, mueren por una enfermedad de transmisión sexual o a causa de las adicciones que adquieren para poder huir de una realidad tan cruel.

El último refugio que ha construido Urmi se denomina Soma, en memoria de una bebé, hija de una trabajadora sexual, que se quemó en su cuna mientras que su madre había salido para atender a un cliente.

Este refugio es diferente a los anteriores, se ha creado específicamente pensando en albergar a niñas que se encuentran en peligro de ser prostituidas, ya que Urmi, en sus múltiples recorridos ha conocido ancianas que nunca han salido del barrio rojo donde viven y en el que ejercen la prostitución desde que eran niñas.

Al crear New Light, no pensé en global, no quería hacer grandes cosas porque de ser así, seguro que no hubiera hecho nada. Simplemente, me centré en hacer pequeñas cosas. Una sola vida restaurada o salvada de la prostitución, 
ya da sentido a todo mi trabajo" (URMI BASU) (Kristof, N. D., \& WuDunn, S.,2012, p.170)

\section{SAKENA YACOOBI}

Era 1995, la época más fuerte del régimen talibán, se encontraban en plena guerra en Afganistán y había, en ese momento, una represión muy fuerte en el país $y$, como consecuencia de esta situación, los talibanes, entre otras medidas, prohibieron a las niñas ir a la escuela.

En medio de circunstancias que podrían desalentar a cualquiera, Sakena, quien había estudiado Biología en Estados Unidos y poseía un Master en Salud Pública, se las ingenió para, desde la clandestinidad, abrir 80 escuelas, formar maestros $y$ crear bibliotecas escolares móviles $y$, por supuesto, secretas.

Fruto de sus esfuerzos, educó en el peor momento de la prohibición a 3800 niñas afganas. Recordemos que todas esas acciones pudieron costarle la vida debido a lo extremo de la prohibición y al estado que se encontraba el país en ese momento.

No fue nada fácil y era arriesgado. Negociaba con la gente para que me cediera casas y protegiera a las escuelas y a las alumnas. Las instruíamos para que no llegaran todas a la vez, sino escalonadamente. No se permitía la entrada de hombres y siempre había alguien de guardia, vigilando. (SAKENA YACOOBI) (Kristof, N. D., \& WuDunn, S.,2012, p.187)

Alentada por su amor a la educación, Sakena creó no solo escuelas, sino incluso una universidad para mujeres y programas de alfabetización de adultos para los refugiados afganos que habían huido del régimen talibán y se encontraban refugiados en Pakistán.

Hoy por hoy, Sakena ha creado el Instituto Afgano de Aprendizaje que educa 350000 niñas y mujeres en todo el país, además de haber formado a 13000 profesores.
Si la mujer tuviera acceso a la educación $y$ tuviera la capacidad de tener un pensamiento crítico, nadie abusaría de ella, porque ella sería capaz de defenderse (SAKENA YACOOBI) (Kristof, N. D., \& WuDunn, S.,2012, p.215)

\section{ALBA STELLA}

La Hna. Alba Stella Barreto lleva un poco más de 30 años trabajando por las comunidades más pobres que crecen en las márgenes del Río Cauca, distrito de Aguablanca, en Cali, Colombia.

En el 2004, la fundación Paz y Bien que la Hna. Alba había creado, recibió la donación de una entidad que deseaba apoyar en la recuperación de jóvenes pandilleros, a través de microcréditos que se les otorgarían para ayudarles a salir adelante y cambiar de vida.

Alba Stella averiguó entonces en diferentes entidades financieras acerca de la forma cómo deberían otorgar los préstamos a las personas beneficiadas, pero se enteró que, para recibir dicha ayuda, debería pagar entre el 30 y $40 \%$ del total del dinero para que le ayudaran a administrar el fondo lo que le pareció excesivo pues reduciría notablemente el dinero y muchas menos personas podrían ser ayudadas.

Sin embargo, la Hna. Stella contaba con la ayuda divina de su lado y un día por casualidad se encontró con el libro El precio de un sueño de David Bornstein. En sus páginas encontró las respuestas que andaba buscando. Se trataba de la historia de Muhammad Yunus, un profesor de economía que en 1971 descubrió que prestando pequeñas cantidades de dinero podía sacar del círculo vicioso de la pobreza a muchos habitantes del área rural de Bangladesh.

Yunus, había fundado el Grameen Bank que hoy cuenta con más de 7,5 millones de personas con microcréditos, demostró que los más pobres de los pobres, en especial las mujeres, son los mejores clientes que puede tener un banco. Un $98 \%$ de ellos devuelve el dinero prestado. Ningún banco conoce tasas de devolución tan altas. 
La Hna. Stella, entonces, decidió tomar la idea de Yunus y aplicarla a los pobres que procuraba ayudar desde hacía ya tantos años. Para lo cual decidió entrevistarse con personas de las más altas esferas, viajar, asistir a congresos, prepararse, etc., ella hizo todo lo necesario, se volvió una experta de cómo debía manejarse un Banco que prestara dinero a los más pobres de entre los pobres.

Afortunadamente, no le faltaron aliados, entre ellos, la Universidad del Valle de Colombia.

Un ejemplo de la forma cómo ayudó su proyecto fueron los hermanos Salazar, campesinos desplazados por el narcotráfico. El negocio de los Salazar consistía en comprar lotes de frutas o verduras para vender en la carrera 10 en Cali. El proceso era el siguiente: En las mañanas hacían un préstamo por $\$ 80.000$ (pesos colombianos) a alguno de los prestamistas "gota a gota" de la zona. Al final del día, luego de vender la mercancía, debían pagar \$140.000 al prestamista. Sólo se quedaban con $\$ 20.000$. Cuando la cooperativa les hizo un préstamo por $\$ 300.000$, con la promesa de que debían aprender a leer y escribir, su suerte comenzó a cambiar.

Hoy, después de tres préstamos más que han pagado en su totalidad y de haber aprendido a leer y escribir, los hermanos Salazar decidieron regresar al campo, cerca del municipio de Ginebra, pues lograron la estabilidad financiera para comprar una parcela y vender sus propios productos.

El convivir tantos años en uno de los sectores más segregados de Cali, llevó a la Hna. Barreto a concluir que una de las trampas más fuertes de la pobreza no es la falta de talento sino la falta de crédito, en Aguablanca había capital humano, pero no capital de trabajo. Por eso lideró una de las experiencias pioneras de microcrédito en su país, que hoy se cristaliza en la Cooperativa Semilla de Mostaza, que ha beneficiado, hasta el momento, a más de dos mil personas.

\section{ANN COTTON}

Ann, lamentablemente, pierde a su hija recién nacida a causa de una enfermedad congénita, esta pérdida la lleva a replantearse su vida. Se anota en un master en educación y como parte de sus actividades educativas debe visitar una zona rural en Zimbabwe, a fin de averiguar a qué se debía el alto índice de ausentismo escolar.

La idea generalizada era, en ese momento, que las hijas no deberían estudiar porque no eran lo suficientemente hábiles para aprovechar y era mejor destinar cualquier dinero existente en la familia a la educación de los hijos varones.

Ann Cotton, durante su visita a Zimbabwe, conoce a dos hermanas que habían caminado 100 kilómetros desde la aldea donde vivían, hasta otra aldea que contaba con escuela gratuita, las hermanas, a fin de poder estudiar, vivían en una choza improvisada y se alimentaban de lo que podían. Ann, impresionada por todo el sacrificio que ambas adolescentes debían hacer para poder recibir educación, comenzó a recolectar dinero para ayudarlas, efectivamente, lo consiguió, pero no solo para ayudar a las dos jóvenes, sino también para apoyar a otras 32 niñas.

Sin embargo, esta ayuda no le pareció suficiente a Ann quien, después de dos años, creó Camfed, la Campaña por la Educación Femenina.

Camfed ha ayudado a 600000 niños y niñas en cinco países africanos a continuar $y / 0$ completar sus estudios, lo que se ha propuesto dicha organización de ayuda no es solamente proporcionarles uniformes, libros, etc. sino brindar un seguimiento al niño o la niña de tal manera que su educación se complete. Son más de 1027 niñas las que no solo han terminado el colegio sino inclusive han concluido carreras universitarias.

La clave de la escuela es que les da confianza en sí mismas, que les dará aliento para abrir sus propios negocios o buscar un trabajo para ser independientes económicamente. Que les ayudará a escoger con quién se casan y cuántos hijos tendrán. Que las impulsará a convertirse en miembros activos de sus comunidades y ayudar, a 
su vez, a otras niñas a seguir sus pasos. (ANN COTTON) (Kristof, N. D., \& WuDunn, S.,2012, p.189)

\section{UNA MADRE DESCONOCIDA}

Es Perú. Una mujer de un poco más de 40 años sube a un microbús para contar que hacía pocos días un carro les había atropellado a ella y a su único hijo adolescente, muestra los golpes que ella misma recibió, le cuesta caminar pero, sube y baja de diferentes carros pidiendo una ayuda económica pues "su niño" como lo llama, está en cuidados intensivos y debe llevar dinero para pagar los medicamentos que necesitará ese día, la voz le tiembla y se percibe un gran dolor en su voz pero, saca las fuerzas de donde casi no las tiene y sigue adelante. Es madre, es mujer, es débil pero también es fuerte, hace lo que debe hacer, a pesar de que ella misma todavía está herida.

¿Quéla hermana con Edna, Urmi, Sakena, Alba y Ann?, bueno, lo evidente, son todas mujeres, pero lo valioso en ellas es que encontraron la forma de canalizar su dolor, de encontrarse a sí mismas en el otro y seguir adelante, ayudando a sus hijos, incluso ayudando a los hijos de otros, sacando adelante sus proyectos, rescatando su vida misma, venciendo la opresión, construyendo la paz.
Entonces, qué sentido tiene educar a mujeres?, pues el mejor de todos, al educarlas, educamos la esperanza, educamos para un mundo más justo, más humano, educamos para revalorizar, para encontrar el equilibrio, para encontrar el justo medio, educamos para construir un mundo mejor.

Haré un nuevo mundo contigo -mi hombre: mi padre, mi esposo, mi hijo, mi hermano, mi amigo, mi compañero y colega,

mi conciudadano-, pero ahora, yo, la mujer, lo haré a mi manera.

Mi modo no se llama imperio, ni los tratos y conflictos y acechanzas entre quienes buscan ser el más poderoso.

Mi palabra de mujer no apunta al poder, sino a engendrar el amor y la vida entre personas humanas. Mi método... busca compartir contigo, en vez de apropiar y codiciar y someter al otro.

Ven otra vez, mi hombre..., como si empezáramos de nuevo, pero ahora hagámoslo juntos.

PEDRO JUAN VILADRICH La palabra de la mujer 


\section{REFERENCIAS}

Antony, C. (2003) La explotación sexual comercial de niños/as y Adolescentes. Panamá: CLADEM.

Fisas, V. (1998) El sexo de la violencia: Género y cultura de la violencia. Barcelona: Icaria.

Galvis, L. (2005) Comprensión de los derechos humanos. Una visión para el siglo XXI. Bogotá: Ediciones Aurora.

Kristof, N. D., \& WuDunn, S. (2012). Half the sky: Turning oppression into opportunity for women worldwide. New York: Alfred A. Knopf.

Kaplan, A. (2001) Mutilaciones genitales femeninas: entre los derechos humanos y el derecho a la identidad étnica y de género. Costa Rica: San José.

Nieto, R. (2010) Revista Temas $N^{o}$ 191: Derechos Humanos y trata de mujeres con fines de explotación sexual.

Osborne, R. (ed.) (2004) Trabajador@s del sexo. Derechos, migraciones y tráfico en el siglo XXI. Barcelona: Bellaterra.

Parrón, N., Bolaños, A., Royo, E., y otros. (2003) Debate sobre Prostitución y Tráfico Internacional de Mujeres: Reflexiones desde una perspectiva de Género. 